Please do not remove this page

RMIT

UNIVERSITY

\title{
Action or inaction: bystander intervention in workplace sexual harassment
}

McDonald, Paula; Charlesworth, Sara; Graham, Tina

https://researchrepository.rmit.edu.au/esploro/outputs/9921862112301341/filesAndLinks?institution=61RMIT_INST\&index=null

McDonald, P., Charlesworth, S., \& Graham, T. (2016). Action or inaction: bystander intervention in workplace sexual harassment. The International Journal of Human Resource Management, 27(5), 548-566. https://doi.org/10.1080/09585192.2015.1023331

Document Version: Accepted Manuscript

Published Version: https://doi.org/10.1080/09585192.2015.1023331

Repository homepage: https://researchrepository.rmit.edu.au

(C) 2015 Taylor and Francis

Downloaded On 2023/04/26 23:45:04 +1000

Please do not remove this page 
Thank you for downloading this document from the RMIT Research Repository.

The RMIT Research Repository is an open access database showcasing the research outputs of RMIT University researchers.

RMIT Research Repository: http://researchbank.rmit.edu.au/

\section{Citation: \\ McDonald, P, Charlesworth, S and Graham, T 2015, 'Action or inaction: bystander intervention in workplace sexual harassment', The International Journal of Human Resource Management.}

See this record in the RMIT Research Repository at:

https://researchbank.rmit.edu.au/view/rmit:30581

Version: Accepted Manuscript

Copyright Statement: ㄷ 2015 Taylor and Francis

Link to Published Version:

http://dx.doi.org/10.1080/09585192.2015.1023331 


\title{
Bystander intervention in workplace sexual harassment
}

\begin{abstract}
A promising approach to the persistent problem of workplace sexual harassment is encouraging interventions by bystanders. Adopting a typology developed by Bowes-Sperry and O'Leary-Kelly (2005) that considers the level of immediacy and involvement of bystander interventions, this study explored 74 detailed descriptions of sexual harassment events that occurred in Australian workplaces. The findings reveal that despite the hidden nature of sexual harassment, there is significant involvement of actors who are not direct targets but their actions are frequently delayed, temporary or ineffective. The study makes two contributions to the study and practice of HRM. First, it provides important evidence of the different ways that bystanders respond to sexual harassment in real workplaces and the relative likelihood of these actions. Second, the study points to relevant contextual features evident in the scenarios described which determine if and how bystanders intervene. We discuss the utility of the bystander framework for future research and practice, including the development of bystander interventions as a potentially innovative response to the persistent and damaging problem of workplace sexual harassment.
\end{abstract}

Keywords: sexual harassment; bystander intervention; management response; complainthandling 


\section{Introduction}

A promising approach to the persistent problem of workplace sexual harassment is encouraging pro-social behaviours by bystanders. In broad terms, bystander interventions focus on how individuals who witness or are told about violence, harassment or other antisocial behaviour can intervene in order to prevent and reduce harm to others (Powell 2011). Although there is a significant body of work on the effectiveness of bystander interventions in responding to dating and domestic violence (Chamberlain 2008; Cornelius and Resseguie 2006; Harvey, Garcia-Moreno and Butchart 2007), little research has addressed how bystanders may prevent or respond to workplace sexual harassment (McDonald and Flood 2012). This is despite the fact that sexual harassment, like interpersonal violence, is a highly gendered phenomenon underpinned by broader notions of inequality and 'cultural misogyny' (Chamberlain, 2008; Gailey and Prohaska, 2006, p. 31).

The under-examination of bystander approaches to sexual harassment is shaped by at least three factors. First, sexual harassment is often concealed in that harassers hide their behaviour and act away from witnesses (Scott and Martin 2006) and relatively few targets report their experiences using formal organisational grievance procedures due to fear of reprisals (Firestone and Harris 2003; Illies, Hauserman, Schwochau and Stibal 2003; Wear, Aultman and Borgers 2007). Second, research on sexual harassment has evolved as largely separate or isolated from work on violence prevention in other spheres in which bystander intervention efforts have been more central (McDonald and Flood 2012). Third, studies addressing the role of bystanders in workplace settings have predominantly focused on decision-making processes, including the way witnesses name and perceive injustices and how they intend to act, rather than on how they actually respond. Furthermore, such studies are often limited by social desirability bias and lack of representativeness. That is, they rely on college students as respondents and use fictional written vignettes where participants, who 
are asked to imagine they are bystanders, report how they might respond to a given scenario (e.g., Diekmann, Sillito Walker, Galinsky and Tenbrunsel 2013; Ryan and Wessel 2012).

In contrast, the current study examines actual events reported by targets of sexual harassment about bystander behaviours in a range of workplaces. The study builds on previous conceptual work which suggests that bystanders may provide social guidance that can influence whether targets report the problem or make a formal legal claim (Goldman 2001), initiate a formal organisational response, intervene during an incident, or later confront the harasser (Bowes-Sperry and O'Leary-Kelly 2005). We adopt a framework developed by Bowes-Sperry and O'Leary-Kelly (2005) of potential bystander responses that occur following the witnessing or learning of sexual harassment. We use the typologies in the framework to categorise specific bystander actions (as well as inactions) evident in detailed descriptions of cases derived from interviews with targets of sexual harassment and formal complaints files of sexual harassment in Australian workplaces. The conceptual framework considers both the levels of involvement and the immediacy of bystander actions, allowing for an examination of when and how bystanders respond. We also examine the contextual circumstances in which bystander interventions do and do not occur.

The study makes three contributions to the study and practice of HRM. First, in utilising the key dimensions of the bystander framework using empirical evidence of actual bystander actions in real workplaces, the study characterises different types of actions taken, contributing to what are currently nascent understandings of how bystanders respond to workplace sexual harassment. Second, by considering the circumstances under which different forms of bystander interventions occur, the study points to features of the workplace context which may determine bystander interventions. Third, we reflect on the utility of the bystander intervention framework for future research and practice, including how pro-social 
responses may be encouraged as part of a comprehensive approach to addressing the persistent and damaging problem of workplace sexual harassment.

\section{Definitions of bystanders and bystander approaches}

Research has consistently demonstrated that despite significant negative consequences, targets of sexual harassment often respond passively, such as avoiding the harasser, minimizing the behaviours or denying them altogether (Bowes-Sperry and O’Leary-Kelly 2005). This is because although targets want the behaviour to cease, they also try to avoid reprisals by the harasser and to maintain their status and reputation in the work environment (O’Leary-Kelly, Paetzold and Griffin 2000; Ragins and Scandua 1995). Because responses by targets of sexual harassment are often passive, organisational approaches which rely exclusively on individual targets bringing forward complaints to management are unlikely to be successful (Benavides-Espinoza and Cunningham 2010). In contrast, enlisting the support of bystanders to intervene during or following an actual event, or encouraging them to report the behaviour through organisational channels on behalf of the individual target, may be an effective way to extend organisational-level efforts to prevent sexual harassment at work (McDonald and Flood 2012).

In the violence prevention literature, bystanders are understood to be individuals who observe an act of violence, discrimination, or other problematic behaviour, but who are not its direct perpetrator or victim (Powell 2011, p. 8). In a recent review of bystander approaches to the more specific problem of workplace sexual harassment, McDonald and Flood (2012) suggested that bystanders may interrupt incidents of sexual harassment or the situations which might lead to harassment; challenge perpetrators and potential perpetrators; provide support to potential and actual victims; and work to change the social norms and inequalities supportive of sexual harassment. Consistent with this broad conceptualisation, we define 
bystanders in this paper as individuals who observe the harassment firsthand, as well as others, both within and outside the workplace, who may directly witness events or who are informed about sexual harassment via the workplace grapevine or via targets themselves who seek emotional support and advice.

Within the workplace, bystanders therefore may include HR managers or line managers, equity/harassment contact officers, and co-workers or customers to whom sexual harassment is reported and/or from whom support or advice is sought. Outside the workplace, bystanders may include friends, partners or family members in whom the target confides and who may potentially intervene in order to prevent and reduce harm (Powell 2011). The rationale for this inclusive conceptualisation of bystanders, which includes direct witnesses and informants both inside and outside the workplace, is two-fold. First, there is strong evidence that sexual harassment has a significant negative psychological impact on observers as well as others who are not direct witnesses (Miner-Rubino and Cortina 2007; Raver and Gelfand 2005). Second, there is difficulty in disentangling direct observation from secondhand knowledge because individuals often fail to distinguish their personal observations from the suggestions of others (Hekkanen and McEvoy 2002).

\section{Explanations of bystander interventions}

Conceptualisations of bystander interventions have proposed the nature of bystander actions themselves, and/or the antecedents to these actions. Bowes-Sperry and O'Leary-Kelly (2005) identified four categories of intervention behaviours based on two dimensions - the level of involvement or immersion in the sexual harassment event (high, low) and the level of immediacy of the intervention (high, low). Definitions and examples for each of the four categories are outlined in Table 1. 
Insert Table 1 about here

Whilst relatively little empirical work has demonstrated how bystanders respond to sexual harassment in actual workplaces, some studies suggest that the kinds of high-level involvement reflected in this model (including actions with both high and low immediacy) occur relatively infrequently (Wear et al. 2007; Handy 2006). A representative Australian prevalence survey, for example, found that more than three-quarters of witnesses to sexual harassment took some form of action consistent with a low immediacy-low involvement response, such as discussing the problem or offering advice to the target (AHRC 2008). However, the study also revealed that behaviours that could be categorised as low immediacy-high involvement, such as formal complaints or directly confronting the harasser, were also reported, albeit less frequently (AHRC 2008). Distinctions between these different levels of bystander involvement, which is to either take public action 'on the social stage of the organisation' (Gardner and Martinko 1998, p. 69) or simply to be ready to privately support the target emotionally or cognitively (Bowes-Sperry and O'Leary-Kelly 2005), are likely to be an important in designing bystander interventions which may reduce the occurrence of sexual harassment.

Bowes-Sperry and O’Leary-Kelly (2005), building on Latane and Darley's (1970) earlier framework, also proposed a potential route to these different forms of observer intervention in sexual harassment. They suggest that observers are influenced by the situation (e.g., ambiguity and moral intensity of the incident, social influence effects); beliefs about whether it is their personal responsibility to act (which is in turn influenced by the harassertarget relationship and social appropriateness); and perceptions of behavioural alternatives and their consequences (e.g., perceived harm, expectations of reoccurrence). Other work, mainly from the organisational psychology literature, has also suggested that bystanders tend 
to deny or minimise sexual harassment and by implication, seem less likely to respond, if it occurs between co-workers rather than between a supervisor and subordinate; if there was a previous relationship between the parties; if the target acquiesces rather than responds assertively; if the target is unattractive; and if the behaviours are ambiguous or not severe (e.g., Benavides-Espinoza and Cunningham 2010; Madera, Podratz, King and Hebl 2007; Rotundo, Nguyen and Sackett 2001; Yagil, Karnieli-Miller, Eisikovits and Enosh 2006). Another more general model of observer's voice responses to injustices by Goldberg, Clark and Henley (2011), which bridges the literature on procedural justice, social identification and voice (e.g., Harlos 2001), suggests there are three decision points where individuals weigh personal and situational costs and the benefits of responding. The model suggests that bystander intervention will be more likely to occur when the observer weighs the value of similarity with the target higher than the costs of associating with a low-status group; prioritises the potential benefits of changing the target's work environment over the costs of being perceived as a trouble-maker; and considers the benefits of improving the work situation more important than the costs of going against the group (Goldberg et al 2011).

In this study, we adopt Bowes-Sperry and O'Leary-Kelly's (2005) model of bystander intervention to focus primarily on the level and immediacy of bystander actions which occurred in response to witnessing or hearing of sexual harassment in a range of workplace settings. Our data, which comprises reports from targets of sexual harassment, precluded testing the individual, micro-level decision-making processes of bystanders which are reflected in some of the process models summarised above. However, the data do reveal some of the workplace circumstances which influenced whether, and how, bystanders responded to the sexual harassment events reported by targets. By revealing such potential determinants of bystander action and inaction, and the different ways that bystanders respond 
in workplaces, the study informs the development of bystander interventions as one component of sexual harassment prevention.

\section{METHODS}

We addressed the following three research questions:

1. How and when do bystanders respond in instances where workplace sexual harassment occurs, and when do they refrain from action?

2. What is the nature and relative frequency of bystander interventions that are characterised as having high/low immediacy and high/low involvement?

3. What contextual features affect bystander interventions and inaction?

\section{Sample and procedure}

Data comprised detailed descriptions of sexual harassment that had occurred in a wide variety of Australian workplaces. These descriptions were derived from two sources: telephone interviews conducted with targets of workplace sexual harassment; and formal sexual harassment complaints lodged with Australian Anti-discrimination Commissions. Interviewees were recruited in a number of ways, including via community advocacy organisations, media contacts and via the project website. Interviewees resided across Australia, necessitating a telephone interview strategy. The duration of interviews was between 45 minutes and 2.5 hours and they were often emotionally charged. Detailed questions covered the nature of the harassment experienced; the process of making a complaint (through organisational or legal channels); short and longer-term financial, occupational and psychological impacts; and the actions of others involved. Our analysis here focuses on the latter theme. Targets were diverse in terms of age, occupation, industry sector and geographic location. However, they were predominantly women ( 25 of 29 interviews). 
Some targets had sought formal redress in response to the sexual harassment, either via organisational or legal channels, whereas other interviewees told their stories to the researchers for the very first time.

The second source of data was detailed descriptions of workplace sexual harassment from all formal complaints lodged with all eight state, territory and federal Australian Antidiscrimination Commissions (48 complaints lodged by women, 6 by men). These sources constituted a census of sexual harassment complaints reported in a six-month time period in Australia (Jun-Dec 2009). Quantitative and qualitative file details were recorded on a comprehensive, 40-item pro forma developed by the researchers that addressed the nature of the SH reported; the characteristics of complainants and respondents; and the handling of the sexual harassment in the organisational context. In some Commissions the researchers were provided with direct access to the paper files, whereas in others, Commission staff collected the data on behalf of the researchers using the pro forma document. No identifying information was recorded during the data collection process and where the researchers had direct access to paper files, confidentiality agreements were in place.

Of the 29 target interview transcripts available, 20 contained information relevant to bystander interventions or inaction, and of the total 284 sources derived from Commissions, 54 contained codable information. Although the different sources (74 in total) examined for the study were reported via different means, the narratives - including the temporal chain of events, the nature of the behaviours, and the actions of the people involved - were virtually indistinguishable in terms of the level of detail provided and on characteristics such as occupation, industry, sex or subjective seriousness of the SH. The vast majority (62 sources, $84 \%$ ) of the data sources analysed involved a male harasser and a female target. Of the remaining 12 sources (16\%), three involved female-on-female sexual harassment, three female-on-male and six male-on-male. Approximately two-thirds of sources involved a 
harasser who was more senior in organisational status than the target (manager, supervisor or employer), whereas around one-third of sources described a harasser who had a more equal power relationship (co-worker/customer) with the target. None of the sources we examined involved a harasser who was junior to the target. A wide range of industry settings (e.g., retail, finance, education), occupational groups (e.g., white collar professional, trades workers) and organisational sizes (e.g., multinational organisations, small businesses), were represented in the data. We identify each quotation with these occupational and organisational identifiers, the data source (interview, commission file) from which it was derived, and the gender of the target. These variables, in addition to detail in the quotations themselves, provide contextual information relevant to the bystander actions reported.

\section{Analysis}

Interview transcripts and qualitative excerpts in Commission files were analysed in a three stage process. First, we identified all sections of text where bystander involvement was reported, either during the sexual harassment event(s), or later during the process of making a formal complaint in a workplace or to a Commission. As noted earlier, we adopted a broad definition of a bystander; that is, an individual within or outside the workplace who had either directly witnessed, or been later informed of the harassment. We found evidence of 130 separate instances of bystander involvement from our 74 data sources. An 'instance' refers to a unique configuration of people involved and workplace circumstances; in some sources there was more than one instance of bystander involvement. Second, each instance of bystander involvement was coded according to the four quadrants in Bowles-Sperry and O'Leary-Kelly's (2005) framework; that is, as high or low involvement and as high or low immediacy. In addition, we identified 68 instances of inaction in 44 data sources, which we allocated to a fifth analytic category, inaction. An instance of bystander inaction comprised 
scenarios where an individual had the opportunity to have involvement (e.g., by attempting to stop the harassment or by supporting the target), but did not do so. This approach provided both a detailed descriptive picture of the varied ways in which bystanders behave in organisational settings, as well as a relative numerical picture of how the 198 instances of intervention and inaction were reflected across each of the five analytic categories.

The third stage of the analysis involved identifying, for each instance of bystander involvement, the gender of the bystander; the bystander-target relationship (e.g., family/friend; peer co-worker; line manager); and the bystander-harasser relationship (senior to the harasser; junior to the harasser; peer relationship; external workplace relationship). The small sample size overall, and the small number of instances in some cells, particularly in the high involvement-high immediacy category where only nine examples were found, prevented us from statistically testing differences between intervention categories on these variables. However, we present these descriptive statistics as totals across all instances of bystander involvement, in support of our primary focus on the nature of bystander action and inaction and the circumstances in which bystander involvement occurred.

\section{Results}

The results detail bystander actions under each of the four categories aligning with the analytic framework. In addition, we identify illustrative instances of inaction and finally, the nature of bystander-target-harasser relationships evident in the data.

\section{Low immediacy-low involvement bystander interventions}

Sixty-four instances of low immediacy-low involvement bystander interventions were identified, constituting the most frequent type of intervention across the four categories. This type of bystander involvement predominantly comprised situations where targets confided in a co-worker or family member/friend about the events. The responses offered by these 
confidantes ranged from sympathising with the target and acknowledging the behaviour sometimes specifically naming the behaviour as sexual harassment - through to advice about what action the target should take. Examples of moral support offered by bystanders included acknowledging that harassers had 'crossed the line' and that they were 'on their side', and understood why they were distressed.

Insert Table 2 about here

The provision of moral support, especially from co-workers, also took the form of sharing information about their own experiences at the hands of the harasser or knowledge of the harasser as a repeat offender in the workplace:

"So I spoke to another girl who was an executive assistant... I said to her 'Look, there's this man on my floor who is making me feel really uncomfortable'. And she said, 'Wait, is his name X?'... She said she felt that the way he was looking at her was in a sexually perverse way and he would block her entrance when she wanted to get up from her desk... I was so happy. I'm not on my own. I'm not alone. People won't think I'm crazy if two people witness it" (Interview, female, professional, large public sector organisation). Advice offered by bystanders took various forms, including a range of individual strategies intended to cease the harassing behaviours, and frequently, assertive and confrontational actions. Targets often reported that they wanted to follow this advice but had been unable to do so, and consequently that they felt their passivity had made them complicit in allowing the harassment to continue:

"Even when I spoke to my manager I felt like I should have said something. He asked me the same question: 'Did you talk to him about it?'... And those sort of questions make you feel... like I had done the wrong thing by not approaching him and talking to him. But I don't feel comfortable talking about 
it to him. I didn't think I needed to talk about it to him" (Interview, female, administrative officer, large public sector organisation).

Other bystander advice was to respond with individual-level, passive strategies such as 'being cold' towards the harasser, ignoring them, brushing them off, inventing an imaginary boyfriend, being careful, or changing the way they dressed. Bystanders also offered advice about coping strategies, such as quitting their job, taking a holiday, sharing the information with their partner, or seeking medical advice/support. Other guidance included using organisational channels, such as providing information about formal organisational procedures/policies, or to begin collecting evidence such as diary entries or emails.

Consistent with previous work (see for example Illies et al. 2003; Fielden, Davidson, Woolnough and Hunt 2010; Hayes 2004; Wear et al. 2007), the data clearly showed that targets were often reluctant to report sexual harassment through organisational channels:

“He [partner] told me 'You shouldn't be having to put up with this kind of behaviour and this filth and this type of language in the workplace'. And he kept insisting that I did something about it but I was a bit concerned because I know how detrimental this man is, I know how vindictive he is. I have seen how he manipulates and how he pushes people out of the department if he doesn't want them there" (Interview, female, nurse, medium private sector organisation).

Several data sources revealed evidence of actual reprisals experienced by bystanders from harassers, supporting the idea that bystanders may be punished for intervening in sexual harassment, even if it was at a low level of involvement and some time following the event. The following description from a witness statement for example, demonstrates that fears of reprisals by bystanders may be well founded: 
"I told a fellow co-worker that [harasser] had propositioned me again. On the Friday night [harasser] came up to me and said, 'Why did you tell them about this?' I was panicked by this and said, 'Look, don't worry, the whole thing is over and done with, I just want to do my job, I am the one who would complain if I wanted it to be official, and I am not going to do that, as I don't want trouble"' (Commission complaint, female complainant, bus driver, transport company).

\section{Low immediacy-high involvement bystander interventions}

Low immediacy-high involvement bystander interventions were the second most frequently reported (41 instances), and primarily involved bystanders reporting the harassment through organisational channels or directly confronting harassers after the event. The following example is illustrative of the role of family members as bystanders. In this particular case, a mother of an adolescent, reported the sexual harassment on behalf of her daughter:

"I told my mother about what had occurred.. [She] rang [organisation] and spoke to a woman I had previously worked with and asked what she should do. She advised her to inform the owners... My mum then explained the situation [to the owners] and her reply was 'Well, we have spoken to him and as you can understand he is a young man with raging hormones and [target] is a very beautiful girl"' (Commission complaint, 16 year old female complainant, cashier, warehouse outlet store).

We also found evidence of family members and also managers and co-workers, directly confronting the harasser. Consistent with the low immediacy component of this category, this was not immediately following the sexual harassment but some time later. 
These actions typically involved telling the harasser to stop their behaviour and/or apologise to the target, as the following witness statement reveals:

"[Harasser] came back from a meeting with his female manager and made the comment, 'I can't believe it, she has legs'. I looked up from my computer and said 'What?' He said, 'We just went to a meeting at a client site and she turned up in a skirt'. I was so annoyed with him. I said 'I'm sure [female manager] won't appreciate you speaking about her like that'... On another occasion... he made the following comments about the blonde woman who worked in recruitment. He said to me, 'Now come on, you can't dress like that and expect guys like me not to have thoughts'. I said 'I somehow don't think that she dresses like that for your entertainment' (Commission complaint, female complainant, professional).

Other evidence of low immediacy-high involvement interventions included line managers escalating a complaint to the HR department or more senior levels of the organisation (with or without the target's approval):

"The complainant complained to her placement officer... She suggested the complainant speak with another manager and that she would attend the meeting with her... The complainant and her placement officer went to see more senior management. They were told an investigation would take place" (Commission complaint, female complainant, room attendant/cleaner, hotel). Co-workers also reported the sexual harassment on behalf of the target and/or offered to accompany the target to report their complaint:

"We [target and co-worker] were also trying to protect our boss... We knew he had done the wrong thing and hadn't done enough. We knew that managers had been disciplined when they hadn't reported things officially when they 
were supposed to so we very carefully went over his head. It was supposed to be taken seriously. So then it went to the ethical standards committee" (Interview transcript, female target, administration officer, large public sector organisation).

In some cases, co-workers also offered high involvement support in the longer term by offering to testify or give witness statements in court. However, as discussed below, this support rarely came to fruition.

\section{High immediacy-low involvement bystander interventions}

Bystander actions that were characteristic of high immediacy-low involvement actions were less frequent than those involving low immediacy actions, and were identified in only 16 instances of bystander intervention. They were generally consistent with following organisational protocols in ways that were intended to end the harassment. However, they were inconsistent with high involvement interventions characterised by more public declarations of the wrongdoing, or by taking a confrontational stand.

Co-workers occasionally interrupted incidents in low-level ways or gave signals to alert the target when they believed a sexually harassing incident may be imminent. Examples included walking purposefully into a room at an opportune time or making nonconfrontational comments intended to interrupt events:

"[Male co-worker] would then give me signals to protect myself. He would pretend to do his button up if he saw that my button was undone or if he caught [harasser] trying to look down my shirt..." (Commission complaint, female complainant, warehouse junior, export company).

"It had reached the stage where, because of his behaviour, some of the people that I worked closely with were aware of the way he was towards me, that he 
was behaving in a bit of a predatory sort of way. And when we'd have morning teas and meetings and stuff like that I'd sit down and they'd sit on either side of me so he couldn't actually sit near me, because that's what he used to like, he used to try and get close to me" (Interview, female, administrator, disability services organisation).

We also found evidence of managers removing either the target or the harasser to another work area or scheduling them on different shifts immediately after they became aware of the harassment, as the following examples illustrate:

"I briefly told my supervisor that he has asked me out to dinner, which was very odd, and they all know that he's got a partner, and I said, 'Look, I just don't want to be sat near him' and so they've shifted everyone, not just me and him. Like they’ve done it in an inconspicuous way which is nice" (Interview, female, administrator, insurance claims office).

"After being called to a meeting with management straight after the altercation, management decided to transfer her to another depot. It was also decided after some consideration by management to immediately separate the parties so that they would not have any further contact or have to work in close proximity while the complainants allegations were being investigated" (Commission complaint, female complainant, crane operator, crane hire company).

There was also evidence of managers addressing the incident(s) privately but directly with the alleged harasser and requesting that they cease the behaviour immediately. For example, in another case involving a female administration officer at a wholesale company, a manager stood down the alleged harasser pending an investigation of the incidents reported and placed the target on paid stress leave. 


\section{High immediacy-high involvement bystander actions}

High immediacy-high involvement bystander interventions were the least frequently reported (9 instances). All of the examples involved co-workers publicly intervening in the wrongdoing, such as challenging the harasser, publicly interrupting a harassment incident, or coming to the target's defence while an incident was occurring, publicly requesting that the harasser be stood down, or directly and immediately telling the harasser to stop their behaviour. Illustrative of this category was the following:

"I employed a junior trainee who was 18 . He started with the company in March. In the first two months I would hear him trying to defend me. He would say to the males in the office, 'You guys have no respect for women'. They would quickly shoot him down in flames saying, 'Are you gay?' or similar taunts. He stopped trying to stand up for me" (Commission complaint, female target, financial controller, construction company).

Occasionally, high immediacy-high involvement bystander interventions did not occur in the workplace but in social situations where work colleagues had congregated, as the following example illustrates:

"At closing time of the hotel while outside on the footpath I was in a discussion with a group of colleagues as to where we were headed next. I saw out of the corner of my eye [harasser] grab her breasts again. I intervened, pushing [harasser] away from her and said to him 'You can't do that!' to which he replied, 'I'm plant manager, I can do what I like!'” (Commission complaint, female complainant, assembly operator, manufacturing plant).

\section{Bystander inaction}


The data revealed 68 instances where direct witnesses to sexual harassment, who had a clear opportunity to speak up or act in defence of the target, did not do so. In sources where inaction was evident, there was often evidence of the harasser holding power or authority over the bystander. The following for example speaks to the way bystanders were fearful of acting because the harasser was likely to react punitively to bystanders who attempted to support targets of sexual harassment:

“He was lovely but very much under [harasser's] command... he wouldn't speak up... because they were so involved and had been with him [the harasser] the longest, kind of like they had this loyalty but they ....still couldn't speak up because they knew what he was like" (Interview, female target, administrative assistant, small private sector organisation).

The following is an excerpt from one source where a manager not only failed to act, but also actively discouraged the target from enlisting the assistance of witnesses to support her version of events:

“They said '...Don't do that. Don't go rounding up and muddying the waters of the investigation'. And I said, 'Well, I have listed them for you to contact'. And she said, 'Well, they haven’t come forward' (Interview, female target, administrative assistant, large public sector organisation).

There were also examples of bystander managers who minimised or reinterpreted the harassing behaviours as just part of the harasser's character, or doubted the target's complaints, sometimes in spite of similar, previous reports by other targets:

"When I said something to the union, she [the manager] said, "Did it actually happen, really?"...They were kind of like doubting me, you know" (Interview, female complainant, production line operator, car manufacturing company). 
"I had told other people at our head office but they would say 'That's just [harasser], he's like that', and when I discussed it with the other girls the exact same thing had happened to them but everyone was too scared to do anything" (Commission complaint, female complainant, office manager, national furniture and electrical goods retailer).

A particularly distressing outcome for targets of bystander inaction, or more accurately, bystanders who were complicit in the harassing conduct, involved situations where bystanders directly witnessed the harassment and not only failed to intervene but subsequently joined in or laughed. The following excerpts illustrate this, the first describing a reaction after a company director exposed himself at a director's lunch in a hotel room:

"They were laughing. They thought it was funny... One of them came to me and claimed to be out on the veranda. It was a blur at the time... I only knew that the other director was sitting at the other end of the table laughing his head off and [state manager] was sitting directly to my right laughing as well” (Interview, female target, professional, medium private sector organisation).

"While I was working at my workstation a subcontractor for the business came into the office... All of a sudden I felt a hand come over my shoulder and place a rolled up bundle of notes in my cleavage... I quickly removed it and kept working. I could hear the males in the office laughing but I could not respond as I was so humiliated... They laughed and said 'Can't believe he was game to do it'.” (Commission complaint, female complainant, financial controller, construction company).

Some bystanders who offered social support to the target also promised public support in a complaint process, often in the form of a witness statement or testifying as part of an organisational investigation, at a Commission conference or in court. Frequently, however, 
bystanders later withdrew their support and/or witness statements when the complaint escalated or became public:

"Some of them were really nice; when I was going to go with a common law claim I asked if they would help me, and they said 'Yes, no worries, we'll help you, we'll support you'. When it came to giving a statement or information, they all lost their memories" (Interview, male target, emergency services worker, public sector organisation).

Where bystanders minimised, reinterpreted or denied the target's version of events, this had a highly negative impact on the target. Feelings of betrayal and disappointment were widely expressed in these scenarios, especially when the bystander had full knowledge of the events. Illustrative of the negative impact on targets is the following account from the father of a young girl who was sexually harassed in a service station where she worked as a console operator:

"In the time that my daughter was employed with [organisation] I watched her become very upset and a different person altogether... On several occasions she came to me and told me she didn't want to go to work because she didn't feel safe. No one should feel this way about a place where they are expected to go and work every day to make a living" (Commission complaint witness statement; Female complainant; service station console operator).

Table 2 summarises the relative frequency of bystander interventions and inaction across these five categories, alongside illustrative examples from the data.

\section{Bystander-target-harasser relationships}


Table 3 details bystander-harasser relationships, and bystander-target relationships for each bystander event. For the two-thirds of instances where the gender of the bystander was evident $^{1}$ ( $n=86$ ), women were more likely to be bystanders compared to men (49 women, 34 men; in three instances both a woman and a man were reported as bystanders). In terms of bystander-harasser relationships, there were relatively few occurrences overall of bystander actions by those who held more senior positions in the organisation to the harasser (15 instances or $12 \%$ ). This was somewhat surprising considering that holding a more senior organisational position than the harasser would seem to justify, or even demand, an active response to sexual harassment. In contrast, peer co-workers (35\%); bystanders junior to the harasser (30\%); and individuals outside the organisation (23\%), were more likely to intervene.

With respect to bystander-target relationships, involvement by family/friends accounted for $21 \%$ of all instances of bystander actions in our sample; a frequency of involvement that was surprisingly high given their substantially lesser proximity to the sexual harassment event(s) that unfolded. However, co-workers of targets were the most likely to act, compared to other categories of bystander-target relationships including line/HR manager, family/friend, or 'others', which included union advocates. The higher propensity of co-workers (of both targets and harassers) to intervene may be due to their closer proximity to the harassing conduct and also its emotional aftermath. However, peer coworkers also accounted for more than half of all instances of inaction, suggesting that proximity does not guarantee bystander action. Evidence for the involvement of line/ HR managers of the target was found in slightly less than one third of bystander interventions, but also one in five instances of inaction.

\footnotetext{
${ }^{1}$ In the remaining third, the gender of the bystander was not obvious. A common example was where the involvement of a line manager was reported but their gender was unspecified.
} 
Insert Table 3 about here

\section{Discussion and Conclusions}

Encouraging pro-social behaviours by bystanders appears to be a promising approach to the persistent problem of workplace sexual harassment. Whilst the effectiveness of bystander interventions in responding to dating and domestic violence has been demonstrated (Chamberlain 2008; Cornelius and Resseguie 2006; Harvey, Garcia-Moreno and Butchart 2007), this study addressed the relative scarcity of research addressing how bystanders may prevent or respond to workplace sexual harassment specifically (McDonald and Flood 2012). The scenarios describing bystander interventions that were examined for the study revealed the level of immediacy and involvement of bystander responses which occurred, details of where bystanders had an opportunity to respond but did not do so, and the relative likelihood of these interventions. In each instance of bystander involvement, the gender of the bystander and the hierarchical or relational position of the bystander relative to the harasser and to the target were identified. The data also point to the contextual circumstances which influenced how bystanders responded to sexual harassment in the workplace. These findings inform the ways in which pro-social responses by bystanders may be encouraged to prevent and respond to workplace sexual harassment.

The data revealed that when an individual is sexually harassed at work, others frequently become involved. These individuals include those with emotional attachments to the target outside the workplace - friends, partners, parents - as well as those within and connected to the organisation, including co-workers, line managers, HR personnel, union advocates and contractors. The findings demonstrate that although sexual harassment is a relatively hidden phenomenon and one characterised by low levels of formal complaints compared to its prevalence (e.g. Firestone and Harris 2003), the ripple effects beyond the 
individual target, even in the absence of formal investigation and public scrutiny, are significant.

With respect to the four categories of bystander involvement, low immediacy-low involvement interventions - the most frequently occurring actions across the four intervention categories - typically involved providing support and advice to targets some time following the immediate sexual harassment event. In contrast, the category revealing the least number of instances, high immediacy-high involvement interventions, involved actions that interrupted an ongoing harassment incident, and observers who showed strong public involvement, such as challenging a harasser directly. Between these extremes, low immediacy-high involvement interventions, while also demonstrating strong involvement publically and socially, typically took place at a later point in time, such as lodging a sexual harassment complaint. These interventions occurred more than twice as often as the final category, high immediacy-low involvement interventions, which were characterised by private support for the target and actions that occurred in a current situation, such as interrupting a sexual harassment incident in subtle ways and with minimal visibility. Instances consistent with the fifth analytic category used in the analysis, which was inaction, were the most frequent of all. Examples typically comprised minimising harassing behaviours or remaining silent during a sexual harassment event.

Overall, the findings demonstrated that responses to workplace sexual harassment by bystanders, while frequent and varied in nature, are often limited in preventing further harassment and/or redressing harm. This was evidenced in the relatively fewer examples of actions with high immediacy and/or high involvement; the experience of bystanders initially offering support and then later withdrawing it; the frequent instances of inaction where there was potential to offer support or intervene; and of most concern, the active co-participation of some bystanders. Though there were exceptions, many of the bystander actions revealed were 
tentative, temporary, delayed or ineffective. Although it remains to be established which types of bystander actions are more effective and in what contexts, research on perceptions of sexual harassment by bystanders, and also literature addressing organisational complaints processes, would suggest that more immediate and more assertive responses are most effective in preventing and redressing sexual harassment in the workplace (e.g., Balogh, Kite, Pickel, Canel and Schroeder 2003; Yagil et al. 2006).

\section{Contextual circumstances influencing different bystander interventions}

The findings revealed four key contextual features of bystander intervention scenarios which affected the likelihood of bystander action occurring, the level of involvement and immediacy of interventions, and/or how some actions shifted over time. Here, we reflect on these features in light of previous work addressing routes to observer intervention.

One contextual feature that appeared to influence bystander intervention was identification with and similarity to the target. These determinants have been suggested as important in the early stages of process models which predict bystander responses (BowesSperry \& O’Leary-Kelly, 2005; Goldberg et al. 2011). Evidence supporting this finding includes the disproportionate number of bystanders who were women, compared to men, and co-workers compared to superiors or subordinates. It could be argued for example that female bystanders, and female co-workers in particular, may identify more strongly with targets (who are similar to themselves in that they are predominantly women) than male co-workers and those in more senior positions. The examples of bystanders who shared experiences of harassment in the same workplace and by the same harasser in the low-involvement, lowimmediacy intervention category are particularly illustrative of both similarity and identification. Though not explicitly accounted for in conceptual models of routes to observer intervention, the data suggests that the actions of targets may also foster identification in 
reverse, where female targets sought out female co-workers in which to confide and seek support, who subsequently responded or intervened as bystanders. Our sample size precluded a gender-based analysis of the different types of interventions used. However, identification on the basis of gender may be an important area of future bystander research because there are indications from the violence prevention literature that masculine norms and identities may reduce the likelihood of male bystanders intervening to assist women, especially if exclusively in the presence of other men, for fear of being seen as unmasculine, weak or gay by their male peers (Carlson 2008).

The experience or anticipation of group-level sanctions appeared to have underpinned several examples in the inaction category where male bystanders did not intervene, or were complicit in the sexual harassment, when targets were being publicly humiliated and degraded. Indeed, the fear of reprisals, sanctions or punitive responses for intervening in response to sexual harassment comprises another relevant circumstantial feature influencing bystander interventions more broadly. Fear of reprisals, which is consistent with conceptualisations of risk perceptions in the later stages of process models which detail how workplace observers respond to perceived injustices (Bowes-Sperry \& O’Leary-Kelly, 2005; Goldberg et al. 2011) also helps explain the large number of low immediacy-low involvement actions. Offers of support or advice, or sharing common experiences of harassment, which featured strongly in low involvement-low immediacy interventions in particular, would likely have been important sources of social support for targets. However, they may also have been offered at the expense of more public and assertive responses within the organisation (Gardner and Martinko 1998) because they did not usually involve significant risks for the bystander in attracting reprisals. Somewhat ironically, this stood in contrast to the many instances where bystanders advised targets themselves that they should respond assertively to harassers because it was the most appropriate and effective course of action. Furthermore, 
examples where bystanders initially promised to support the target publically should a complaint escalate, but later withdrew their support, were almost certainly related to the perceived negative consequences for doing so. The withdrawal of support over time also demonstrates how fear of reprisals may lead to a shift from low-involvement interventions to inaction.

Another relevant contextual feature of bystander interventions which appeared to influence whether bystanders intervened at all, as well as their level of involvement, was workplace norms, particularly norms related to the tolerance of gender-based hostility and sexualised behaviours. Workplace norms are not explicitly outlined in process models of observer intervention, which tend to focus on individual-level constructs. However, previous research from the sexual harassment literature suggests that effective prevention requires attention to the gender climate of the workplace, including a commitment to gender equality goals, defining policies in gender-specific terms where power differentials are taken into account, and providing explicit opportunities for women to collectively and democratically challenge prevailing regimes and strive for an inclusive environment (Eveline and Booth 2002; Zippel 2003). That sexual harassment remains accepted, or at least tolerated in some workplaces goes some way towards explaining the examples in the inaction category whereby managers advised targets and bystanders to ignore the harassing conduct and/or reinterpreted the behaviours described in the complaint process as being understandable or simply consistent with the harasser's character. Conversely, high-involvement examples of line managers who pro-actively escalated complaints to more senior organisational levels and co-workers who reported the sexual harassment on behalf of the target, were indicative of workplace norms where gendered hostility was considered less acceptable. Workplace norms indicating tolerance of sexual harassment were also evident in the examples of managers and co-workers not only failing to intervene, but co-participating in the harassing conduct; 
scenarios that had particularly humiliating and degrading effect on targets. Such minimisation, reinterpretation and co-participation is part of the "practice of gendering" in the organisation of work (Bacchi and Eveline 2009, p. 573) and appears to constrain assertive bystander involvement which is effective in preventing and redressing sexual harassment.

The examples of inaction and/or co-participation in sexualised ridicule may also be indicative of bystanders weighing up the social appropriateness of intervening. This variable is identified in Bowes-Sperry and O'Leary-Kelly's (2005) decision model at the point where the observer decides if it is their responsibility to act. The example of the young man who initially challenged sexual harassment by stating his co-workers had no respect for women, but later remained silent after they insinuated he was gay, also illustrates how perceived or demonstrated social appropriateness of intervening may influence a shift from interventions that are high-immediacy, high-involvement, to inaction.

A further relevant feature, the proximity to the sexual harassment event(s), also appeared to influence the immediacy of bystander interventions. Whilst not accounted for in models describing routes to observer intervention, high immediacy interventions, particularly those that involved interactions with the harasser directly, such as challenging or interrupting an actual or potential sexual harassment scenario, required circumstances where (co-workers, usually) were physically present as the interaction unfolded. The secrecy of sexual harassment, which often occurs in private (Scott and Martin 2006), means that there are often fewer direct witnesses, or those with close proximity to the sexual harassment conduct, than bystanders who hear about the harassment via other means. This limits opportunities for bystanders to immediately intervene. However, the greater likelihood of co-workers, in contrast to managers or individuals external to the workplace, being physically present when sexual harassment occurs, suggests that proximity is an important factor to consider in developing opportunities for immediate interventions by bystanders. 


\section{Limitations and future research}

The descriptions of sexual harassment derived from targets did not allow for a consideration of all variables identified in models describing routes to bystander intervention, especially individual-level decision processes by bystanders. Nor could we assess some circumstantial factors such as the ambiguity (Bowes-Sperry and O'Leary-Kelly 2005) or seriousness of the sexual harassment and whether this prompted bystander action. This is because perceptions of seriousness may depend on a range of subtle factors not consistently evident in the data such as the duration of the harassment, whether the harassment was physical and/or nonphysical and the emotional resilience of the target. However, one relevant individual-level (similarity/identification) and four workplace-level (fear of reprisals, workplace gender norms, proximity to the sexual harassment events, social appropriateness of intervention) contextual features were identified as influencing bystander responses to sexual harassment. Future case study research which focuses at the workplace or industry level would yield further and important new insights into the way localised, contextual features of workplaces influence opportunities for pro-social bystander responses.

Clearly, much remains to be learned about how jurisdictional, workplace, and individual-level attributes may impact on the likelihood and effectiveness of bystander responses in preventing and appropriately responding to workplace sexual harassment. However, the addition of the bystander inaction category is, we argue, a critical category of bystander 'intervention' that should be adopted in future research. As this study has shown, inaction was not a neutral response, but rather had significant consequences for the target and the organisation, and sometimes featured as part of a continuum of behavioural responses where initial interventions shifted to inaction. Considering where inaction occurs also effectively illuminates the barriers and challenges to effective action and hence, opportunities for changes to workplace systems, structures and cultures that are likely to support them. 


\section{Implications for HRM practice}

The study has important implications for the study and practice of HRM in terms of the prevention of and responses to workplace sexual harassment. The framework adopted for the study appears to have significant utility in (i) characterising the different ways that bystanders behave when witnessing or being otherwise informed of sexual harassment in everyday workplaces; (ii) the relative extent to which the behaviours occurred in terms of timing (immediacy) and intensity (involvement); and (iii) the characteristics of the individuals who do and who could intervene. Through the consideration of the circumstances in which these bystander interventions and inaction occurred, the study has also pointed to important individual and workplace-relevant determinants of different forms of bystander responses and how they may shift over time. Indeed, the systems and dynamics of organisational settings powerfully structures and constrains the ability of targets and bystanders to respond effectively to sexual harassment and prevent further harm (McDonald and Flood 2012), especially in high-involvement and high-immediacy ways.

Variations in what is possible and realistic in terms of the development of bystander interventions by organisations and human resource managers may also vary across legal jurisdictions. Whilst laws proscribing sexual harassment in Australia, where this study was conducted, are similarly defined and operationalised in many other industrialised economies, even subtle differences in legal statutes and frameworks, such as formal complaint mechanisms, vicarious liability provisions and typical remedial responses such as the level of financial compensation provided to victims, may impact on bystander behaviours in the workplace. Hence, any developments to encourage bystander interventions in workplace sexual harassment necessarily needs to take the specific legal context into account. 
The study provides preliminary support for three recommendations for encouraging effective pro-social responses from bystanders in order to prevent workplace sexual harassment and redress its harms. First, strategies should consider how a wide range of actors within the workplace, as well as external to it, can be encouraged to intervene. High immediacy actions in particular, can best be promoted amongst those with greater proximity to sexual harassment events, especially co-workers. Second, taking into account the constraints of workplaces themselves, there is a need for more assertive (high involvement) responses by those with organisational influence, who are less likely to face reprisals for their actions and who have the authority to shift workplace norms to those that are intolerant of gender-based hostility. These bystanders include line managers, senior managers and HR personnel who either witness sexual harassment directly, or are otherwise informed of circumstances where it may have occurred. Third, effectively promoting bystander intervention strategies, especially those with high immediacy and high involvement, rests on assurances of safety and protection from many of the same reprisals that targets themselves anticipate and experience. These protections should be explicitly defined and mandated throughout the organisation. The substantial potential for bystanders who witness or who are informed of sexual harassment, or indeed other anti-social workplace behaviours, to intervene in order to prevent and reduce harm to others (Powell 2011), rests heavily on these developments and strategies. 


\section{References}

Australian Human Rights Commission (2008), Effectively Preventing and Responding to Sexual Harassment: A Code of Practice for Employers, Sydney, Australia: AHRC.

Bacchi, C., and Eveline, J. (2009), Mainstreaming Politics: Gendering Practices and Feminist Theory, Adelaide: University of Adelaide Press.

Balogh, D., Kite, M., Pickel, K., Canel, D. and Schroeder, J. (2003), 'The Effects of Delayed Report and Motive for Reporting on Perceptions of Sexual Harassment', Sex Roles, $48,337-348$.

Benavides-Espinoza, C., and Cunningham, G. (2010), 'Bystanders' Reactions to Sexual Harassment', Sex Roles, 63, 201-213.

Bowes-Sperry, L., and O’Leary-Kelly, A. (2005), 'To Act or Not to Act: The Dilemma Faced by Sexual Harassment Observers', Academy of Management Review, 30, 288-306.

Carlson, M. (2008), 'I'd rather go along and be considered a man: Masculinity and bystander intervention, Journal of Men's Studies, 16(1), 3-17.

Chamberlain, L. (2008), A Prevention Primer for Domestic Violence: Terminology, Tools, and the Public Health Approach, VAWnet: The National Online Resource Center on Violence Against Women (March).

Cornelius, T., and Resseguie, N. (2006), 'Primary and Secondary Prevention Programs for Dating Violence: A Review of the Literature', Aggression and Violent Behavior, 12, 364-375.

Diekmann, K., Sillito Walker, S., Galinsky, A. and Tenbrunsel, A. (2013), Double victimization in the workplace: Why observers condemn passive victims of sexual harassment, Organization Science, 24(2), 614-628.

Eveline, J., and Booth, M. (2002). 'Gender and sexuality in discourse of managerial control: the case of women miners'. Gender, Work \& Organization, 9(5), 556-78. 
Fielden, S., Davidson, M., Woolnough, H., and Hunt, C. (2010), 'A Model of Racialized Sexual Harassment of Women in the UK Workplace', Sex Roles, 62, 20-34.

Firestone, J., and Harris, R. (2003), 'Perceptions of Effectiveness of Responses to Sexual Harassment in the US Military, 1988 and 1995', Gender, Work and Organisation, 10, $42-64$.

Gailey, J. And Prohaska, A. (2006), "'Kocking off a fat girl”: An exploration of hogging, male sexuality and neutralizations. Deviant Behavior, 27, 31-49.

Goldberg, C., Clark, M., and Henley, A. (2011), 'Speaking Up: A Conceptual Model of Voice Responses Following the Unfair Treatment of Others in Non-Union Settings', Human Resource Management, 50, 75-94.

Goldman, B. (2001), 'Toward an Understanding of Employment Discrimination Claiming: An Integration of Organisational Justice and Social Information Processing Theories', Personnel Psychology, 54, 361-386.

Handy, J. (2006), 'Sexual harassment in Small-Town New Zealand: A Qualitative Study of Three Contrasting Organisations', Gender, Work and Organisation, 13, 1-24.

Harlos, K. (2001), 'When Organisational Voice Systems Fail: More on the Deaf-Ear Syndrome and Frustration Effects', Journal of Applied Behavioral Science, 37, 324342.

Harvey, A., Garcia-Moreno, C., and Butchart, A. (2007), Primary Prevention of Intimatepartner Violence and Sexual Violence, background paper for WHO Expert Meeting, May 2-3, 2007.

Hayes, P. (2004), Taking It Seriously: Contemporary Experiences of Sexual Harassment in the Workplace, Research Report 2003/2004.

Hekkanen, S., and McEvoy, C. (2002), 'False Memories and Source-Monitoring Problems: Criterion Differences', Applied Cognitive Psychology, 16, 73-85. 
Illies, R., Hauserman, N., Schwochau, S., and Stibal, J. (2003), 'Reported Incidence Rates of Work-Related Sexual Harassment in the United States: Using Meta-Analysis to Explain Reported Rate Disparities', Personnel Psychology, 56, 607-618.

Latane, B. \& Darley, J. (1970). The unresponsive bystander: Why doesn't he help? New York: Appleton-Century-Crofts.

Madera, J., Podratz, K., King, E., and Hebl, M. (2007), 'Schematic Responses to Sexual Harassment Complainants: The Influence of Gender and Physical Attractiveness', Sex Roles, 56, 223-230.

McDonald, P. and Flood, M. (2012). Encourage. Support. Act. Bystander approaches to sexual harassment in the workplace. Sydney, Australia: Australian Human Rights Commission.

Miner-Rubino, K., and Cortina, L. (2007), 'Beyond Targets: Consequences of Vicarious Exposure to Misogyny at Work', Journal of Applied Psychology, 92, 1254-1269.

O’Leary-Kelly, A., Paetzold, R., and Griffin, R. (2000), 'Sexual Harassment as Aggressive Behavior: An Actor Based Perspective', Academy of Management Review, 25, 372388.

Powell, A. (2011), Review of Bystander Approaches in Support of Preventing Violence Against Women, Victorian Health Promotion Foundation.

Ragins, B., and Scandura, T. (1995), 'Antecedents and Work-Related Correlates of Reported Sexual Harassment: An Empirical Investigation of Competing Hypotheses', Sex Roles, 32, 429-455.

Raver, J., and Gelfand, M. (2005), 'Beyond the Individual Victim: Linking Sexual Harassment, Team Processes and Team Performance', Academy of Management Journal, 48, 387-400. 
Rotundo, M., Nguyen, D., and Sackett, P. (2001), 'A Meta-Analytic Review of Gender Differences in Perceptions of Sexual Harassment', Journal of Applied Psychology, 86, 914-922.

Ryan, A. and Wessel, J. (2012), 'Sexual orientation harassment in the workplace: When do observers intervene?' Journal of Organizational Behavior, 33, 488-509.

Scott, G., and Martin, B. (2006), 'Tactics Against Sexual Harassment: The Role of Backfire', Journal of International Women's Studies, 7, 111-125.

Wear, D., Aultman, J., and Borgers, N. (2007), 'Retheorising Sexual Harassment in Medical Education: Women Students' Perceptions at Five US Medical Schools', Teaching and Learning in Medicine, 19, 20-29.

Yagil, D., Karnieli-Miller, O., Eisikovits, Z., and Enosh, G. (2006), 'Is that a 'No’? The Interpretation of Responses to Unwanted Sexual Attention', Sex Roles, 54, 251-260.

Zippel, K. (2003). 'Practices of implementation of sexual harassment policies: individual versus collective strategies'. The Review of Policy Research, 20(1), 175-97. 
Table 1. Bystander intervention framework

\section{<<< Involvement $\gg>>$}

\section{High immediacy-low involvement:}

Interventions that occur in a current situation and

that focus on the interruption of an ongoing

harassment incident; involves private support

without a public connection to the incident(s).

Examples: Redirecting the harasser's attention away from the conduct in a non-confrontational

way; removing the target from the situation;

\section{$\hat{\wedge}$ interrupting the incident without naming the}

conduct as harassment or becoming involved.

\section{Low immediacy-low involvement:}

Interventions that take place at a later time and

that attempt to prevent future harassment;

involves private support without public

connection to incident(s).

Examples: Covert efforts to separate the target/harasser; giving private advice to target (e.g., to avoid harasser or report the incident) without personal involvement; social support behind the scenes.

\section{High immediacy-high involvement:}

Interventions that occur in a current situation and that focus on the interruption of an ongoing harassment incident; observers show strong involvement in a public and social sense.

Examples: Challenging the harasser, telling him/her directly to stop the harassment; publicly naming the conduct as sexual harassment; publicly encouraging the target to report; taking an active and identifiable role.

\section{Low immediacy-high involvement:}

Interventions that take place at a later point in time and that attempt to prevent future harassment; observers show strong involvement in a public and social sense.

Examples: Reporting the harassment on the target's behalf; offering to accompany the target when they report; confronting the harasser after the incident.

Where a bystander has an opportunity to intervene

\section{Bystander inaction} or act on behalf of, or to support a target, but who does not do so.

*Definitions for the four categories of bystander interventions derived from Bowes-Sperry and O'Leary-Kelly (2005). 
Table 2. Frequencies and percentages of data sources and instances for each category of bystander intervention and inaction, including examples of each.

\begin{tabular}{|c|c|c|c|c|c|}
\hline Category & $\begin{array}{l}\text { *Sources } \\
\mathrm{N}=74\end{array}$ & $\%$ & $\begin{array}{l}\text { *Instances } \\
\mathbf{N}=130\end{array}$ & $\%$ & Examples from the data \\
\hline $\begin{array}{l}\text { Low immediacy- } \\
\text { low involvement }\end{array}$ & 38 & 52 & 64 & 49 & $\begin{array}{l}\text {-Sympathising with the target } \\
\text {-Acknowledging the behaviour as } \mathrm{SH} \\
\text {-Offering advice on how to respond and cope } \\
\text {-Sharing own experiences of SH }\end{array}$ \\
\hline $\begin{array}{l}\text { Low immediacy- } \\
\text { high involvement }\end{array}$ & 32 & 44 & 41 & 32 & $\begin{array}{l}\text {-Reporting on behalf of the target through } \\
\text { organisational channels } \\
\text {-Directly confronting harasser after the event to } \\
\text { stop the behaviour or apologise } \\
\text {-Escalating a complaint through org channels } \\
\text {-Accompanying a target making a complaint } \\
\text {-Offering to give witness statements / testimony }\end{array}$ \\
\hline $\begin{array}{l}\text { High immediacy- } \\
\text { low involvement }\end{array}$ & 14 & 19 & 16 & 12 & $\begin{array}{l}\text {-Giving signals that SH may occur } \\
\text {-Removing harasser to another area or shift } \\
\text {-Addressing the incident privately with the } \\
\text { harasser } \\
\text {-Interrupting SH in non-confrontation ways }\end{array}$ \\
\hline $\begin{array}{l}\text { High immediacy- } \\
\text { high involvement }\end{array}$ & 9 & 12 & 9 & 7 & $\begin{array}{l}\text {-Challenging the harasser in front of witnesses } \\
\text {-Coming to target's defence } \\
\text {-Publicly requesting the harasser be stood down }\end{array}$ \\
\hline $\begin{array}{l}\text { Non-involvement } \\
\text { / inaction }\end{array}$ & 44 & 59 & 68 & 52 & $\begin{array}{l}\text { - Minimising or reinterpreted the harassing } \\
\text { behaviours as part of the harasser's character } \\
\text {-Remaining silent during a SH event } \\
\text {-Withdrawing offer of support or witness } \\
\text { statement }\end{array}$ \\
\hline
\end{tabular}

*Totals are not provided as different categories of intervention and more than one instance of intervention, were often identified in a single data source. 
Table 3. Relationship of bystanders to harassers and targets with respect to interventions and inaction.

\begin{tabular}{|c|c|c|c|c|c|c|c|c|c|}
\hline \multirow{2}{*}{$\begin{array}{l}\text { Bystander- } \\
\text { harasser } \\
\text { rel'ship }\end{array}$} & \multicolumn{2}{|c|}{ Interventions } & \multicolumn{2}{|c|}{ Inaction } & \multirow{2}{*}{$\begin{array}{l}\text { Bystander- } \\
\text { target rel'ship }\end{array}$} & \multicolumn{2}{|c|}{ Interventions } & \multicolumn{2}{|l|}{ *Inaction } \\
\hline & Instances & $\%$ & Instances & $\%$ & & Instances & $\%$ & Instances & $\%$ \\
\hline $\begin{array}{l}\text { Senior to } \\
\text { harasser }\end{array}$ & 15 & 12 & 7 & 11 & $\begin{array}{l}\text { Line/HR } \\
\text { Manager }\end{array}$ & 40 & 31 & 13 & 20 \\
\hline $\begin{array}{l}\text { Junior to } \\
\text { harasser }\end{array}$ & 39 & 30 & 27 & 44 & Co-worker & 59 & 45 & 39 & 63 \\
\hline Peer to harasser & 46 & 35 & 18 & 29 & Family/friend & 27 & 21 & 6 & 10 \\
\hline External to org & 30 & 23 & 10 & 16 & Other & 4 & 3 & 4 & 7 \\
\hline Total & 130 & 100 & $* 62$ & 100 & & 130 & 100 & 62 & 100 \\
\hline
\end{tabular}

*In 6 instances of inaction the bystander-target relationship was not clear. 